\title{
Low tidal volume ventilation with low PEEP during surgery may induce lung inflammation
}

Hitoshi Sato ${ }^{1,4}$, Kyota Nakamura ${ }^{1,2}$, Yasuko Baba ${ }^{1,3}$, Shoko Terada ${ }^{1,4}$, Takahisa Goto ${ }^{1}$ and Kiyoyasu Kurahashi ${ }^{1,4,5^{*}}$

\begin{abstract}
Background: Compared to conventional tidal volume ventilation, low tidal-volume ventilation reduces mortality in cased of acute respiratory distress syndrome. The aim of the present study is to determine whether low tidal-volume ventilation reduces the production of inflammatory mediators in the lungs and improves physiological status during hepatic surgery.

Methods: We randomly assigned patients undergoing hepatectomy into 2 groups: conventional tidal-volume vs. low tidal-volume (12 vs. $6 \mathrm{~mL} \cdot \mathrm{kg}^{-1}$ ideal body weight) ventilation with a positive end-expiratory pressure of $3 \mathrm{~cm} \mathrm{H}_{2} \mathrm{O}$. Arterial blood and airway epithelial lining fluid were sampled immediately after intubation and every $3 \mathrm{~h}$ thereafter.
\end{abstract}

Results: Twenty-five patients were analyzed. No significant changes were found in hemodynamics or acid-base status during the study. Interleukin-8 was significantly elevated in epithelial lining fluid from the low tidal-volume group. Oxygenation evaluated immediately after admission to the post-surgical care unit was significantly worse in the low tidal-volume group.

Conclusions: Low tidal-volume ventilation with low positive end-expiratory pressure may lead to pulmonary inflammation during major surgery such as hepatectomy.

Trial registration: The effect of ventilatory tidal volume on lung injury during hepatectomy that requires transient liver blood flow interruption. UMIN000021371 (03/07/2016); retrospectively registered

Keywords: Cytokines, Hepatectomy, Systemic Inflammatory Response Syndrome, Ventilator-Induced Lung Injury, Micro-sampling Method

\section{Background}

In acute respiratory distress syndrome (ARDS), ventilation with a low tidal volume $\left(\mathrm{V}_{\mathrm{T}}\right)$ reduces mortality compared to a conventional $\mathrm{V}_{\mathrm{T}}[1,2]$. Recent studies have shown that ventilation with a conventional tidal volume is also associated with sustained cytokine production in the lungs in patients without lung injury at the onset of mechanical ventilation [3-6]. Furthermore, incidences of lung injury

\footnotetext{
* Correspondence: kiyok@med.yokohama-cu.ac.jp

'Departments of Anesthesiology and Critical Care Medicine, Yokohama City University Graduate School of Medicine, 3-9 Fukuura, Kanazawaku, Yokohama, Japan

${ }^{4}$ Present address: Department of Anesthesiology, Yokohama City University Medical Center, Kanagawa, Japan

Full list of author information is available at the end of the article
}

have been reported after major surgery in those without any pre-existing lung diseases [7]. In those studies [3-6], the protective ventilation strategy consists of low $V_{T}$ ventilation, relatively high positive end-expiratory pressure (PEEP), and lung recruitment maneuver. During hepatectomy, however, surgeons require low PEEP to reduce bleeding from cut surface of the liver [8]. Our question was: when high PEEP, one part of lung protective approaches, is unavailable, does the low tidal volume ventilation strategy have utility? To answer the question, we proposed a study that aimed to evaluate the effect of low tidal volume ventilation during surgery under the condition with a restricted PEEP level $\left(3 \mathrm{cmH}_{2} \mathrm{O}\right)$.

We conducted a prospective, randomized controlled study on patients undergoing hepatic surgery under two 
different $\mathrm{V}_{\mathrm{T}}$ ventilation conditions assigned randomly to determine whether low $\mathrm{V}_{\mathrm{T}}$ ventilation reduces lung injury and improves lung physiology during hepatic surgeries. The primary outcome of the present study was the change in pro-inflammatory cytokine concentrations in the lungs. Secondary outcomes were oxygenation during and immediately after the surgery and the duration of hospital stay after the surgery. We hypothesized that (a) proinflammatory mediators increase in the circulation after hepatic surgery with the Pringle maneuver that causes a temporal hepatic blood flow interruption; (b) airway inflammation is induced when a conventional $\mathrm{V}_{\mathrm{T}}$ is used during surgery; and (c) compared to conventional $V_{T}$ ventilation, low $V_{T}$ ventilation during hepatectomy reduces airway inflammation and prevents lung injury under a condition of a limited PEEP.

\section{Methods}

\section{General protocol and patients}

This prospective, randomized, controlled study was performed at Yokohama City University Hospital. The data were collected from October 2008 to September 2009, with approval from the institutional review board (Date of IRB approval: 08-01-2007; approval number: 07-021), and written informed consent was obtained from all the patients preoperatively.

Patients aged between 20 and 85 years, undergoing hepatectomy, were considered eligible for enrolment in this study. Patients with an American Society of Anesthesiologists' physical status (ASA-PS) value of 3 and above, pre-existing lung disease, tumor in the portal vein or inferior vena cava, requirement of bile duct or gastrointestinal tract repair, or requirement of additional surgical procedures other than hepatectomy were excluded.

Patients were randomly assigned to those ventilated with a $\mathrm{V}_{\mathrm{T}}$ of $12 \mathrm{~mL}$ per predicted body weight (kg) (TV12) or with a $V_{T}$ of $6 \mathrm{~mL}$ per predicted body weight (TV6). The assignment was performed using a random number table by an investigator who was not involved in data collection and was notified to anesthesiologists who were not involved in the study using an envelope method. The investigators who collected the data and samples were blinded to the ventilation settings at any time of the experiment. Mechanical ventilation was performed in a volume-controlled mode, with the ratio of the duration of inspiration to the duration of expiration (I/E) of 1:2 and an end-inspiratory pause time of $10 \%$, using an anesthesia machine (Drager Fabius GS, Drager Medical, Telford, PA, USA). The patients did not receive premedication. Propofol $2 \mathrm{mg} \bullet \mathrm{kg}^{-1}$, vecuronium $0.1 \mathrm{mg} \cdot \mathrm{kg}^{-1}$, and fentanyl $100 \mu \mathrm{g}$ was administered to facilitate orotracheal intubation with a cuffed tube. General anesthesia was maintained with sevoflurane 0.6-1.5 \% and was supplemented by epidural anesthesia with mepivacaine.
The target arterial partial oxygen pressure $\left(\mathrm{PaO}_{2}\right)$ of approximately $150 \mathrm{mmHg}$ was attained by adjusting the inspired oxygen fraction $\left(\mathrm{F}_{\mathrm{I}} \mathrm{O}_{2}\right)$ and the arterial partial carbon dioxide pressure $\left(\mathrm{PaCO}_{2}\right)$ was maintained between 35 and $45 \mathrm{mmHg}$ by changing the ventilation frequency referring to the previous blood gas analysis and end-tidal carbon dioxide pressure. PEEP was applied at $3 \mathrm{~cm} \mathrm{H}_{2} \mathrm{O}$ in both the groups. Ephedrine was administered when the systolic blood pressure dropped below $80 \mathrm{mmHg}$. Methylprednisolone $\left(8 \mathrm{mg} \cdot \mathrm{kg}^{-1}\right)$ was administered intravenously prior to the Pringle maneuver (obstruction of both branches of the hepatic artery and portal vein). Muscle relaxation was reversed with neostigmine and atropine when surgery was completed. Lungs were recruited manually with approximately $20 \mathrm{cmH}_{2} \mathrm{O}$ for 15 to $20 \mathrm{~s}$ prior to extubation in both groups.

\section{Blood sampling and blood gas analysis}

Arterial blood was drawn just prior to bronchoscopic microsampling (BMS), and blood gas analysis (BGA) was performed (model 860, Chiron Diagnostics, Emeryville CA, USA) every $3 \mathrm{~h}$ thereafter. Whole blood was centrifuged at $4{ }^{\circ} \mathrm{C}$ at $3000 \mathrm{RPM}$, and the plasma was aliquoted and stored at $-80{ }^{\circ} \mathrm{C}$ until use. When the patient arrived in the post-anesthetic care unit (PACU), BGA was repeated.

\section{Bronchoscopic microsampling method Epithelial lining fluid sampling}

Epithelial lining fluid (ELF) was collected with BMS probes using a previously reported method [9]. Briefly, a BMS probe was inserted into the channel of a fibreoptic bronchoscope that was inserted into the tracheal tube. The tip of the BMS probe was attached to a segmental bronchus of the right middle lobe under optical guidance of a bronchoscope for $20 \mathrm{~s}$. The BMS probe was then withdrawn from the bronchoscope. These procedures were repeated 3 times using 3 different BMS probes. The tips of the BMS probes, made of cotton, were inserted into pre-weighed test tubes. The tubes were sealed, weighed again with the probe tips, and stored at $-80{ }^{\circ} \mathrm{C}$. The collections were performed immediately after intubation and after 3 and $6 \mathrm{~h}$.

\section{Determination of the sample weight and ELF extraction}

One milliliter of distilled water was added to each test tube containing BMS probes. The tubes were centrifuged at $4{ }^{\circ} \mathrm{C}$ for $10 \mathrm{~min}$, and the supernatant was collected and aliquoted. The BMS probes were dried on a bench top at room temperature for 3 days and weighed. The weight of the collected sample was calculated using the following formula:

$\mathrm{S}=\left(\mathrm{T}+\mathrm{P}_{1}\right)-\mathrm{T}-\mathrm{P}_{2}$, where $\mathrm{S}$ is the sample weight, $\mathrm{T}$ is the weight of the tube, $\left(T+P_{1}\right)$ is the weight of the tube 
and the BMS probes after sampling, and $\mathrm{P}_{2}$ is the weight of the dried probes after extraction. A sample dilution factor (DF) in distilled water was then calculated as follows:

$$
\mathrm{DF}=(\mathrm{S}+1000) / \mathrm{S},
$$

where $S$ is the sample weight in milligrams.

\section{Measurements of mediator concentrations in the blood and ELF}

Cytokines and adhesion molecules were measured using an enzyme-linked immunosorbent assay (ELISA). Tumor necrosis factor (TNF)- $\alpha$ (Quantikine Human TNF- $\alpha$ / TNFSF1A, R\&D Systems, Minneapolis, MN, USA), interleukin (IL)-8 (EH2IL8, Thermo Scientific, Rockford, IL, USA), and intercellular adhesion molecule (ICAM)-1 (EH5400, Thermo Scientific) levels were measured according to the manufacturer's instructions.

\section{Clinical data collection}

Preoperative data were collected from routine clinical documentation that was stored in the institutional medical record system. Intraoperative physiological and ventilatory data were recorded in a data sheet.

\section{Statistical analysis}

All data were statistically analyzed using Statcel $2^{\text {nd }}$ edition (OMS Publishing, Tokorozawa, Japan). The student $t$-test and Mann-Whitney $U$ test were used to assess quantitative variables. Variables measured only once were compared using an unpaired $t$-test. Variables that were measured repeatedly were compared using two-way repeated measures analysis of variance (ANOVA) followed by Bonferroni post hoc. Results were expressed as mean \pm standard deviation; $p<0.05$ was considered significant.

\section{Results}

Patient demography

A total of 28 patients were enrolled, and 14 patients were assigned to each group (Fig. 1). Three patients in the TV12 group were excluded because the operation was terminated before the completion of the study due to dissemination of tumor to the peritoneum. No differences

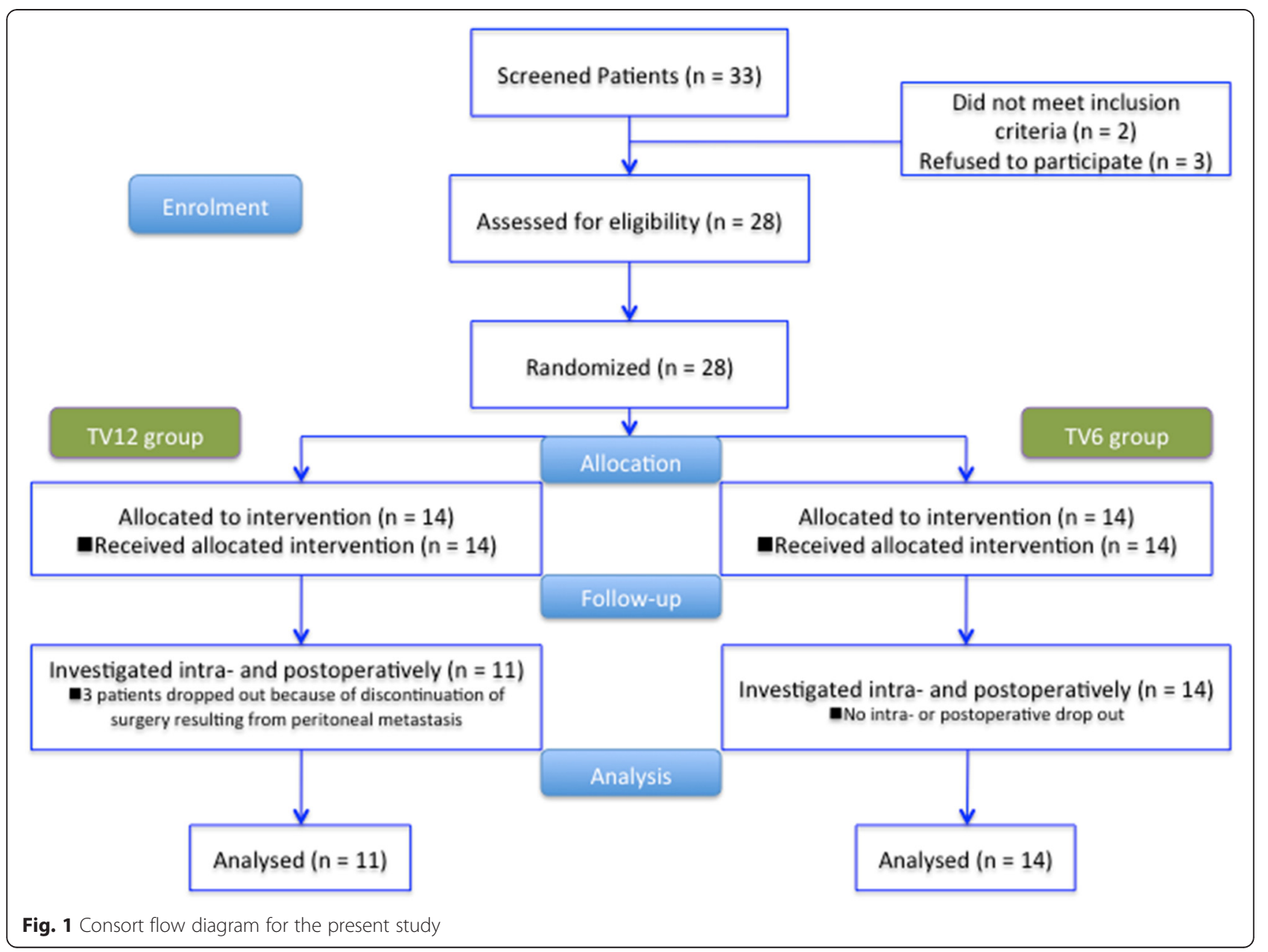


were present in the demographic or clinical data between the groups (Table 1).

\section{Physiological parameters}

No significant differences were found in $\mathrm{pH}$, bicarbonate concentration, heart rate, or blood pressure between the groups (Fig. 2). The $\mathrm{F}_{\mathrm{I}} \mathrm{O}_{2}$ was set between 0.3 and 0.5 in all patients. There was no significant difference in the $\mathrm{P} / \mathrm{F}$ ratio (Fig. 3a) or the $\mathrm{PaCO}_{2}$ (Fig. 3b) between the two groups at any time point. Peak airway pressure was significantly higher in the TV12 group than in the TV6 group (Fig. 3c). To maintain the $\mathrm{PaCO}_{2}$ within the normal range, ventilation frequency was greater in the TV6 group than in the TV12 group (Fig. 3d). All patients were extubated in the operating room and were spontaneously breathing when they arrived at the PACU. The P/F ratio evaluated just after admission to the PACU was higher in the TV12 group than in the TV6 group (417 \pm 92 versus $315 \pm$ 49, $p=0.009$ ) (Fig. 4).

\section{Biological parameters}

No significant difference was found in the plasma concentration of IL-8 ( $p=0.17)$ (Fig. 5a). TNF- $\alpha$ was below the detection limit $\left(1.6 \mathrm{pg} \cdot \mathrm{mL}^{-1}\right)$ in the plasma and ELF samples obtained from all the patients. Elastase activity in the plasma was minimal in both the groups. ICAM-1 in the plasma was significantly higher in the TV6 group than in the TV12 group ( $p=0.03$; Fig. $5 b)$. The concentration of IL-8 in the ELF was significantly higher in the TV6 group than in the TV12 group at $6 \mathrm{~h}(p=0.03)$ (Fig. $6 \mathrm{a})$. No significant difference was found in ICAM-1 $(p=0.31)$ or elastase activity $(p=0.7)$ in the ELF between the groups (Figs. 6b, c).

Table 1 Patient characteristics and the baseline P/F ratio

\begin{tabular}{|c|c|c|c|}
\hline & TV 12 & TV 6 & $P$-value \\
\hline Age,year $^{a}$ & $69(60 / 68)$ & $63(59 / 72)$ & 0.3 \\
\hline Gender (male/female) ${ }^{b}$ & $8 / 3$ & $10 / 4$ & 0.94 \\
\hline Body weight,kg & $57.5 \pm 10.2$ & $62.7 \pm 10.7$ & 0.25 \\
\hline Height,cm & $164.5 \pm 10.1$ & $166.1 \pm 6.9$ & 0.66 \\
\hline Body mass index, $\mathrm{kg} \cdot \mathrm{m}^{-2}$ & $21.2 \pm 2.7$ & $22.6 \pm 2.6$ & 0.22 \\
\hline Operation time, $\min$ & $512.8 \pm 113.9$ & $419 \pm 199.3$ & 0.23 \\
\hline Anesthesia time, min & $606.1 \pm 128.0$ & $525.2 \pm 207.3$ & 0.32 \\
\hline Blood loss, mL & $852.0 \pm 465.0$ & $852.0 \pm 466.4$ & 0.39 \\
\hline Baseline $\mathrm{P} / \mathrm{F}$ ratio & $501.6 \pm 23.9$ & $435.8 \pm 27.6$ & 0.09 \\
\hline Liver resection amount, \% & $38.5 \pm 8.8$ & $33.0 \pm 17.4$ & 0.38 \\
\hline Pringle maneuver, times ${ }^{c}$ & $3(3 / 5.5)$ & $4(3 / 6)$ & 0.75 \\
\hline $\begin{array}{l}\text { Length of hospital stay after } \\
\text { operation, days }\end{array}$ & $12.5 \pm 5.6$ & $15.2 \pm 9.0$ & 0.38 \\
\hline
\end{tabular}

Values are indicated as the mean \pm SD otherwise indicated Age ${ }^{a}$ is represented as the mean (range), gender ${ }^{b}$ as a number, and Pringle maneuver ${ }^{\mathrm{c}}$ as median $\left(25^{\text {th }}\right.$ and $75^{\text {th }}$ percentiles)

\section{Sharing our data}

Data supporting our findings are available upon request.

\section{Discussion \\ Main findings}

The main findings of this study are:

1. Low tidal-volume ventilation during hepatectomy induced an increase in the concentration of IL-8 in the ELF collected during hepatectomy.

2. Low tidal-volume ventilation during hepatectomy resulted in a lower $\mathrm{P} / \mathrm{F}$ ratio after surgery.

These were contrary to our hypothesis that low $\mathrm{V}_{\mathrm{T}^{-}}$ ventilation would reduce lung inflammation and preserve physiological lung functions following major surgery, compared to conventional ventilation.

\section{The mechanism of lung injury}

Our hypothesis was based on studies that showed the benefits of low $V_{T}$ ventilation in ARDS patients [1]. A considerable number of ARDS cases originate from extrapulmonary complications including pan-peritonitis, cholecystitis, multiple injury, and massive transfusion. Severe systemic inflammation is a common occurrence in these conditions. Ischemia-reperfusion of organs or other parts of the body are the leading causes of systemic inflammation. The liver is one of the largest organs in the human body; approximately $25 \%$ of the entire blood flows into the liver. Therefore, repeated hepatic ischemia-reperfusion may be a major cause of systemic inflammation. Takeuchi and colleagues showed polymorphonuculear cell (PMN) recruitment in the lungs, proinflammatory cytokine elevation in the blood and lung homogenates, and pulmonary edema in mice after $90 \mathrm{~min}$ of liver ischemia and reperfusion [10]. Our previous study showed that lung injury occurs following repeated hepatic ischemia and reperfusion with high $V_{T}$ ventilation in rats [11]. Taken together, hepatic surgeries performed with the Pringle maneuver is a potential leading cause of lung injury; therefore, reducing $\mathrm{V}_{\mathrm{T}}$ during hepatectomy is a reasonable strategy to prevent lung injury.

\section{Protective ventilation during surgery}

Recently, several studies have been conducted regarding $\mathrm{V}_{\mathrm{T}}$ and lung functions during surgery. Michelet and colleagues showed that concentrations of IL-8, IL-6, and TNF- $\alpha$ in the plasma were lower in patients who underwent esophagectomy with lower $\mathrm{V}_{\mathrm{T}}$ ventilation $(5 \mathrm{~mL} \cdot \mathrm{kg}$ ${ }^{-1}$, PEEP $5 \mathrm{~cm} \mathrm{H}_{2} \mathrm{O}$ ) than in those who underwent esophagectomy with higher $\mathrm{V}_{\mathrm{T}}$ ventilation $\left(9 \mathrm{~mL} \cdot \mathrm{kg}^{-1}\right.$, PEEP $0 \mathrm{~cm} \mathrm{H}_{2} \mathrm{O}$ ) during one-lung ventilation [12]. Wolthuis and colleagues showed that the concentration of IL-8 in broncho-alveolar lavage (BAL) fluid was significantly 

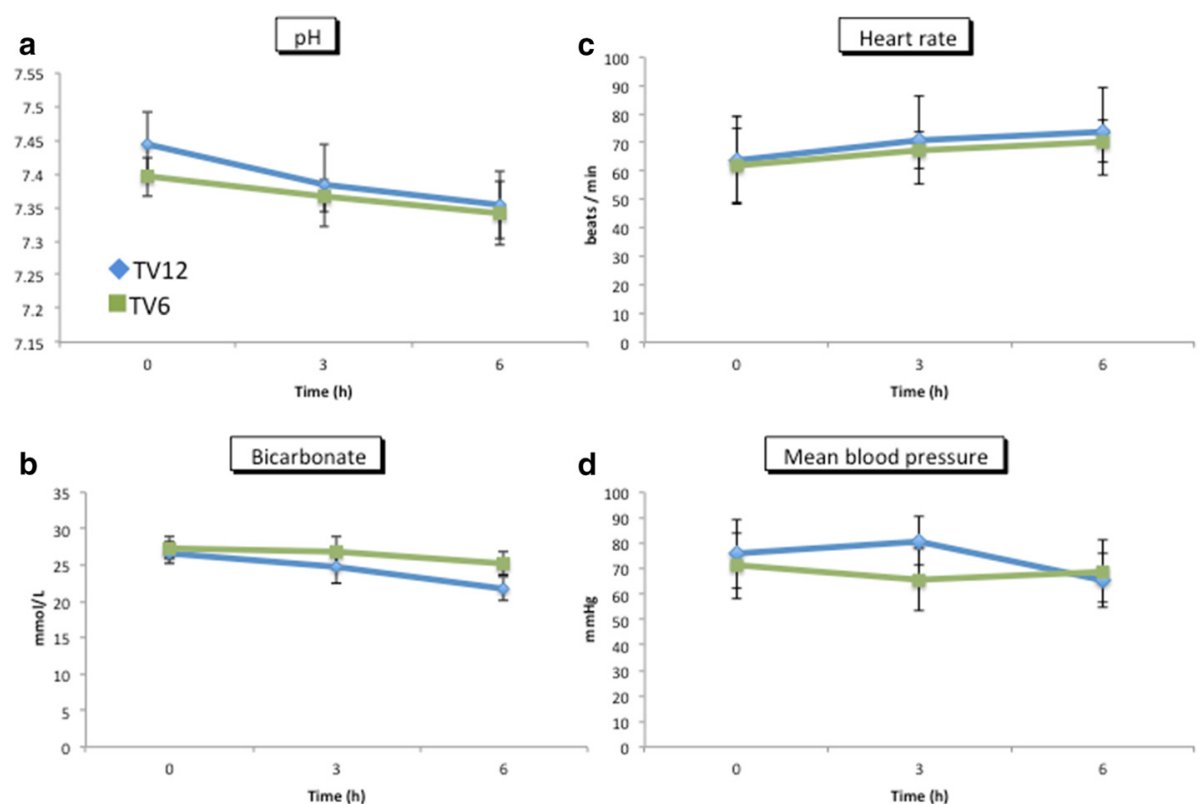

Fig. 2 Changes in hemodynamics and BGA data. pH (a) and bicarbonate (b) were analyzed by blood gas analyses, whereas heart rate (c) and mean blood pressure (d) were obtained from a bedside monitor. Mean \pm standard deviation. No significant differences were observed in BP, HR, or BGA between the groups

lower in patients ventilated with a low $\mathrm{V}_{\mathrm{T}}\left(6 \mathrm{~mL} \cdot \mathrm{kg}^{-1}\right.$, PEEP $10 \mathrm{~cm} \mathrm{H}_{2} \mathrm{O}$ ) than in those ventilated with a large $\mathrm{V}_{\mathrm{T}}$ $\left(12 \mathrm{~mL} \cdot \mathrm{kg}^{-1}\right.$, PEEP $\left.0 \mathrm{~cm} \mathrm{H}_{2} \mathrm{O}\right)$ during elective surgery [13]. Severgnini and colleagues reported that low $\mathrm{V}_{\mathrm{T}}$ ventilation $\left(6-8 \quad \mathrm{~mL} \cdot \mathrm{kg}^{-1}\right.$, PEEP $\left.\quad 6-8 \quad \mathrm{~cm} \quad \mathrm{H}_{2} \mathrm{O}\right)$ during abdominal surgery improved postoperative pulmonary function and reduced the modified Clinical Pulmonary Infection Score as compared with a standard ventilation strategy $\left(10-12 \mathrm{~mL} \cdot \mathrm{kg}^{-1}\right.$, PEEP $\left.0 \mathrm{~cm} \mathrm{H}_{2} \mathrm{O}\right)$ [14]. A recent, randomized controlled trial showed that ventilation with a
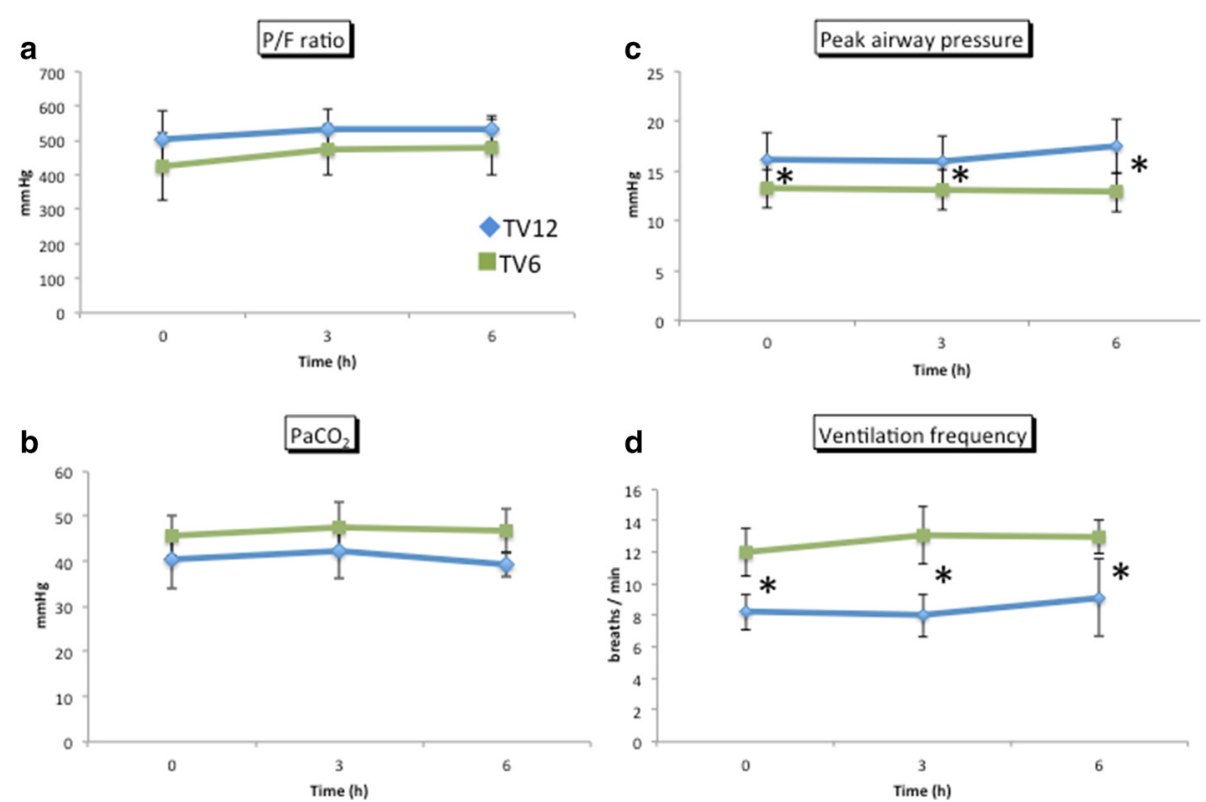

Fig. 3 Changes in arterial blood gases, airway pressure, and ventilation frequency. a Changes in the $\mathrm{P} / \mathrm{F}$ ratio were calculated by $\mathrm{PaO}_{2}$ analyzed by a blood gas analyzer and $\mathrm{FIO}_{2}$. $\mathbf{b}$ Changes in $\mathrm{PaCO}_{2}$ were analyzed by a blood gas analyzer. $\mathbf{c}$, $\mathbf{d}$ Changes in peak airway pressure and ventilator frequency. Mean \pm standard deviation. Peak airway pressure was significantly higher in the TV12 group. Ventilation frequency was greater in the TV6 group than in the TV12 group 


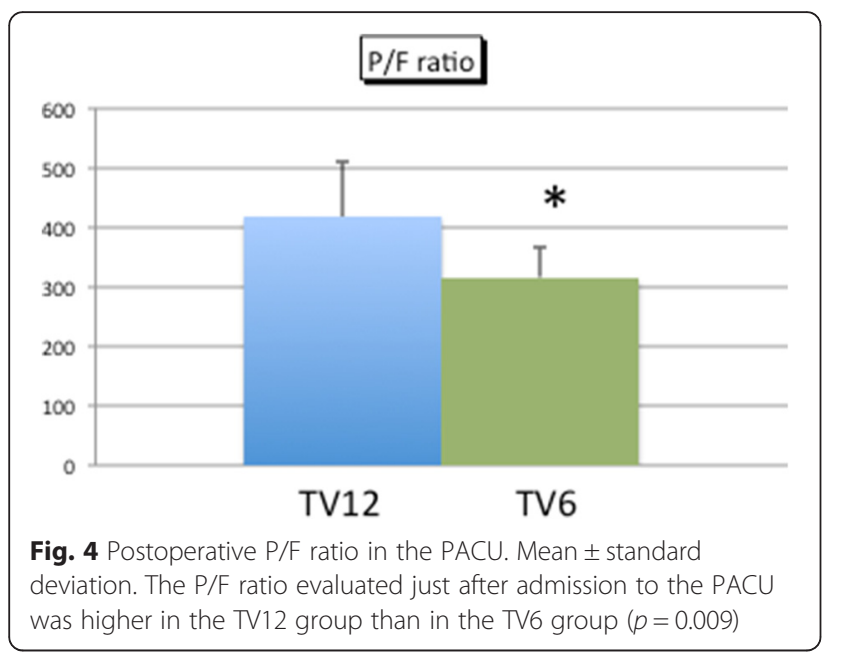

$\mathrm{V}_{\mathrm{T}}$ of 6 to $8 \mathrm{~mL}$ per $\mathrm{kg}$ of predicted body weight with a PEEP of 6 to $8 \mathrm{~cm}$ of $\mathrm{H}_{2} \mathrm{O}$ and a recruitment maneuver reduced major pulmonary complications after abdominal surgery compared to ventilation with a $V_{T}$ of $10-12 \mathrm{~mL}$ per $\mathrm{kg}$ of predicted body weight with no PEEP and no recruitment maneuver [15]. These studies reported that low $\mathrm{V}_{\mathrm{T}}$ ventilation during surgery results in reduced inflammation or better lung functions after the surgery as compared with relatively higher $V_{T}$ ventilation. We should note

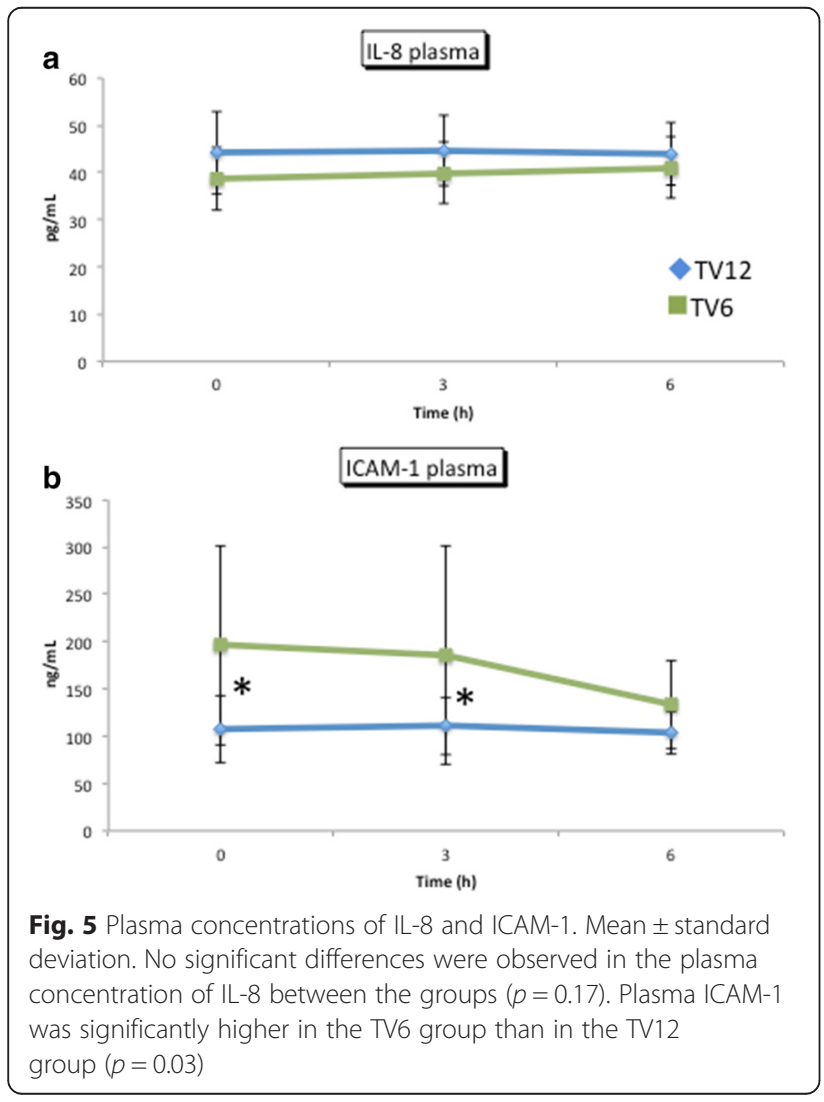

that relatively higher PEEP and/or lung recruitment maneuver were applied to the groups that are ventilated with lower $\mathrm{V}_{\mathrm{T}}$ in those papers [12-15].

The results of the present study were in contrast to those of previous studies in terms of the correlation between the level of $\mathrm{V}_{\mathrm{T}}$ and the post-surgical lung function. The most plausible reason for the discrepancy is the level of PEEP that was applied in the present study. We used relatively low PEEP $\left(3 \mathrm{cmH}_{2} \mathrm{O}\right)$ in both the groups, which may have influenced the results. Recently, there are a few papers that focused on the relationship between PEEP level during surgery and postoperative pulmonary complications in otherwise healthy patients. Ladha et al. retrieved anesthesia records and compared ventilation settings with respiratory complications [16]. Protective ventilation defined as a median PEEP of 5 $\mathrm{cmH}_{2} \mathrm{O}$ or more, a median tidal volume of less than $10 \mathrm{~mL} \cdot \mathrm{kg}^{-1}$ of predicted body weight, and a median plateau pressure of less than $30 \mathrm{cmH}_{2} \mathrm{O}$ was associated with a decreased risk of postoperative respiratory complications. de Jong et al. retrieved anesthesia records and compared median PEEP of $<5 \mathrm{cmH}_{2} \mathrm{O},=5 \mathrm{cmH}_{2} \mathrm{O}$, or $>$ $5 \mathrm{cmH}_{2} \mathrm{O}$ with respiratory outcome [17]. Application of PEEP $>5 \mathrm{cmH}_{2} \mathrm{O}$ was associated with a significant lower odds of respiratory complications and decreased hospital length of stay in patients undergoing major abdominal surgery but not in patients undergoing craniotomy. These findings suggest that special consideration such as application of PEEP of $5 \mathrm{cmH}_{2} \mathrm{O}$ or higher is necessary especially when abdominal surgery is undergone. More recently, a meta-analysis revealed that a protective lung ventilation, low $V_{T}$ ventilation concomitant with PEEP and intermittent recruitment maneuver, showed a significant reduction in incidences of postoperative lung infection, atelectasis, acute lung injury, and length of hospital stay; whereas, low $\mathrm{V}_{\mathrm{T}}$ alone failed to reduce some of the incidences [18]. In the present study, low $\mathrm{V}_{\mathrm{T}}$ ventilation with low PEEP applied to patients undergoing hepatectomy failed to improve pulmonary function, which is consistent with the previous findings [16-18]. Moreover, it is important to understand that optimal $\mathrm{V}_{\mathrm{T}}$ or PEEP for otherwise healthy patients undergoing surgery could be different from those for ARDS patients with a baby lung.

\section{Mechanism of deteriorated lung function}

After $6 \mathrm{~h}$ of ventilation, we found that IL-8 in the ELF was higher in the TV6 group than in the TV12 group. Previous studies have shown an increase in IL-8 levels in atelectatic lungs. Lung collapse results in increased IL-8 levels in BAL fluid and the re-expansion of the lungs further increases IL-8 levels in rabbits [19]. One-lung ventilation resulted in an IL- 8 increase in the ELF of the non-ventilated lungs [20]. These observations suggest that the increase in IL-8 levels in the ELF in the low $V_{T}$ 

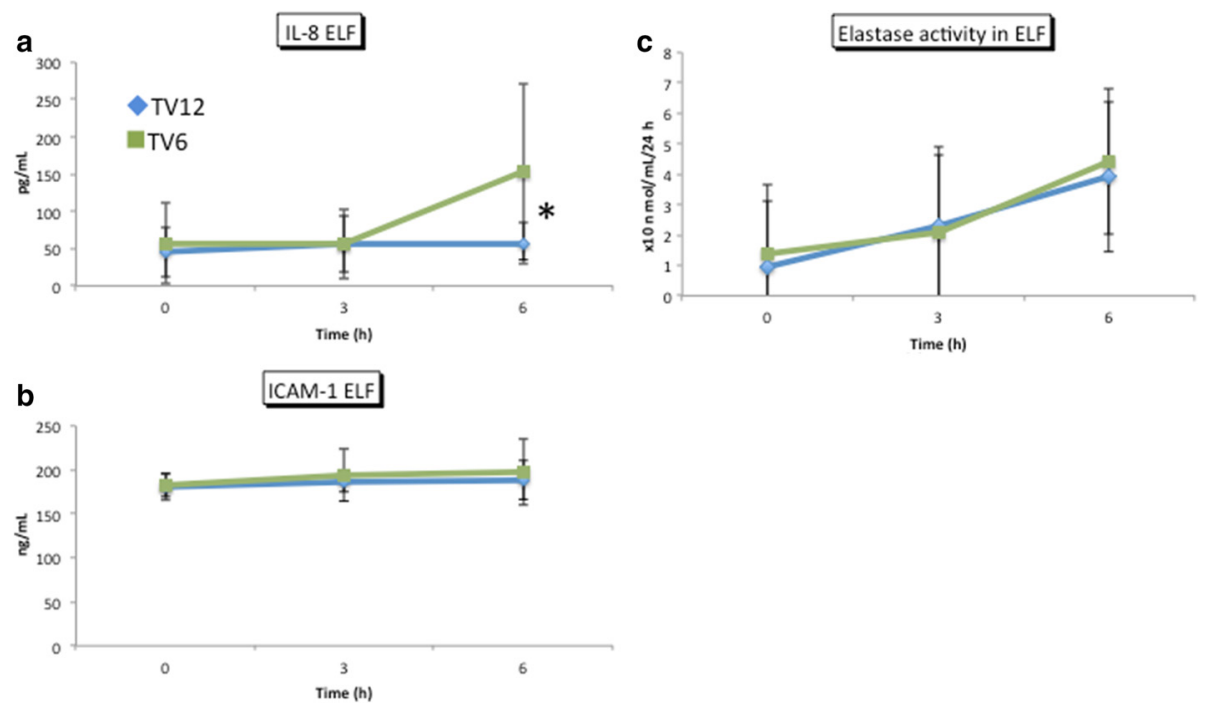

Fig. 6 Concentrations of IL-8, ICAM-1, and elastase activity in the ELF. Mean \pm standard deviation. The concentration of IL-8 in the ELF was significantly higher in the TV6 group than in the TV12 group $(p=0.04)$ and the post hoc analysis revealed a significant difference at $6 \mathrm{~h}(p=0.03)$. No significant difference was observed in ICAM-1 $(p=0.31)$ or elastase activity $(p=0.7)$ in the ELF

group in the present study was due to a repeated lung collapse and re-opening of the lungs (atelectrauma) during surgery due to low $\mathrm{V}_{\mathrm{T}}$ ventilation concomitant with low PEEP. ICAM-1 in the plasma was significantly higher in the TV6 group than in the TV12 group. Plasma ICAM-1 is associated with poor clinical outcomes in patients with acute lung injury [21]. In that study, however, plasma ICAM-1 level is also elevated in the patients with hydrostatic pulmonary edema, who basically have minimal lung injury. In the present study, mean plasma ICAM-1 concentrations in the TV12 and TV6 were from 107 to $117 \mathrm{ng} / \mathrm{mL}$ and from 133 to $196 \mathrm{ng} / \mathrm{mL}$, respectively. These values were identical to that for the patients with hydrostatic pulmonary edema in the previous study (median $177 \mathrm{ng} / \mathrm{mL}$ ) [21], suggesting that the effects of plasma ICAM-1 in the present study on lung injury are minimal in both groups.

\section{Advantages of BMS method over BAL collection}

Historically, BAL fluid has been used to assess the biochemical status of the airway; however, we collected bronchial ELF using the BMS method to assess lung inflammation in this study. There are a few advantages of BMS method over BAL collection. First, concerns have been raised related to patient safety during BAL collection, including desaturation during the procedure, surfactant breakdown, and a spreading of localized pathology. In fact, Bauer and colleagues showed a decrease in the $\mathrm{PaO}_{2} / \mathrm{F}_{\mathrm{I}} \mathrm{O}_{2}$ ratio after $\mathrm{BAL}$ collection, regardless of the BAL volume used [22]. Second, it is not possible to quantitate the concentration of biomarkers in the airway because the exact dilution factor may not be obtained in this way. Lastly, it is inappropriate to obtain repeated BAL measurements within a short period of time because the biomarkers are washed out. In the BMS method, ELF is collected using an absorptive probe guided by a fiberoptic scope; thus, we were able to safely and repeatedly collect biochemical markers from the patients' airways. In contrast to BAL, BMS has the following advantages when used to determine the biochemical status of the airway: oxygenation can be maintained during and after the procedure; alveolar surfactant is preserved; quantification of the biochemical markers is possible; and samples can be repeatedly obtained within a short duration [9].

\section{Limitations of the study}

The present study has a few limitations. First, we did not find a relevant paper to refer to in terms of the standard deviations of the two groups and thus we did not perform power analysis. Accordingly, there may be type-two error in the results of the study. Second, a steroid was administered prior to the Pringle maneuver. It is mandatory to administer a steroid for hepatectomy at our institute, regardless of the study; however, this may have limited systemic inflammation in both of the groups. In fact, in both groups, TNF- $\alpha$ levels in the plasma were below the detection limit, and IL-8 levels in the plasma during the surgery were similar to that of baseline values. Third, in the previous paper, the median plasma SICAM-1 concentrations for survivor and non-survivor among patients with ARDS were $338 \mathrm{ng} / \mathrm{mL}$ and $737 \mathrm{ng} / \mathrm{mL}$, respectively [21], whereas the plasma ICAM-1 values of our patients in each group were far fewer than those values in the 
previous paper namely those of survivors. This fact suggests that although there was significant difference in plasma ICAM-1 in two groups in our study, the extent of the increase in ICAM-1 may not have clinical or biological significance. However we have not proven this and slightly elevated plasma ICAM-1 in the TV6 group may be the cause of lower $\mathrm{P} / \mathrm{F}$ ratio after the surgery. Lastly, postoperative oxygenation difference was the only clinical outcome between the groups. No patient experienced hypoxia postoperatively because each patient received supplemental oxygen at the PACU. However, the data suggest some patients, especially those in the TV6 group (mean P/F ratio of about 300), may have experienced hypoxia unless supplemental oxygen was applied. We may consider this as clinically significant.

\section{Conclusion}

In conclusion, $\mathrm{V}_{\mathrm{T}}$ of $6 \mathrm{~mL} \cdot \mathrm{kg}^{-1}$ predicted body weight ventilation with a PEEP of $3 \mathrm{cmH}_{2} \mathrm{O}$ during hepatectomy caused inflammation in the airway and reduced oxygenation after the surgery, whereas $V_{\mathrm{T}}$ of $12 \mathrm{~mL} \cdot \mathrm{kg}^{-1}$ ventilation with a PEEP of $3 \mathrm{cmH}_{2} \mathrm{O}$ did not. There appears to be more lung inflammation with low tidal volume with low PEEP, which may be due to repeated alveolar collapse and re-expansion (i.e., atelectrauma). Our study supports the findings of other investigations looking at lung protective ventilation during surgery, mainly that low PEEP levels may be harmful. Careful consideration is warranted when enforcing a lung-protective strategy during major surgery.

\section{Abbreviations \\ ANOVA, analysis of variance; ARDS, acute respiratory distress syndrome; $\mathrm{BAL}$, broncho-alveolar lavage; BGA, blood gas analysis; BMS, bronchoscopic microsampling; DF, dilution factor; ELF, epithelial lining fluid; ELISA, enzyme-linked immunosorbent assay; $\mathrm{F}_{1} \mathrm{O}_{2}$, inspired oxygen fraction; I/E, the ratio of the duration of inspiration to the duration of expiration; ICAM-1, intercellular adhesion molecule-1; IL, interleukin; $\mathrm{PaCO}_{2}$, arterial partial carbon dioxide pressure; PACU, post-anesthetic care unit; $\mathrm{PaO}_{2}$, arterial partial oxygen pressure; PEEP, positive end-expiratory pressure; PMN, polymorphonuculear cell; TNF, tumor necrosis factor; TV12, patients ventilated with a $V_{T}$ of $12 \mathrm{~mL}$ per predicted body weight; TV6, patients ventilated with a $V_{T}$ of $6 \mathrm{~mL}$ per predicted body weight; $V_{T}$, tidal volume}

\section{Acknowledgements}

We thank the doctors in the Department of Anesthesiology and the Department of Gastroenterological Surgery, Yokohama City University Hospital, Yokohama, Japan for their helpful assistance.

\section{Funding}

This work was supported by the Center for Advanced Medical Promotion of the Yokohama City University Graduate School of Medicine (grant number: 07-021) and the Grants-in-Aid for Scientific Research from the Japan Society for the Promotion of Science (grant number: 26462368).

\section{Availability of data and material}

Data supporting our findings are available upon request.

\section{Authors' contributions}

HS: study design, collection of data, drafting the work; KN: collection of data; YB: collection of data, revising the work critically for important intellectual content; ST: anesthetizing the study patients, revising the work critically for important intellectual content; TG: study design, revising the work critically for important intellectual content; KK: organizing the study group, study design, performed random assignment of patients, obtained funding, revising the work critically for important intellectual content. All authors have read and approved the manuscript.

\section{Competing interests}

The authors declare that they have no competing interests.

\section{Consent for publication}

Not applicable

\section{Ethics approval and consent to participate}

This study was reviewed and approved by the review board of Yokohama City University (Date of IRB approval: 08-01-2007; approval number: 07-021), and all the patients provided written, informed consent preoperatively.

\section{Author details}

'Departments of Anesthesiology and Critical Care Medicine, Yokohama City University Graduate School of Medicine, 3-9 Fukuura, Kanazawaku, Yokohama, Japan. ${ }^{2}$ Present address: Advanced Critical Care and Emergency Center, Yokohama City University Medical Center, Kanagawa, Japan. ${ }^{3}$ Present address: Operation Department, Yokohama City University Medical Center, Kanagawa, Japan. ${ }^{4}$ Present address: Department of Anesthesiology, Yokohama City University Medical Center, Kanagawa, Japan. ${ }^{5}$ Present address: Division of Critical Care Medicine, Yokohama City University Medical Center, Kanagawa, Japan.

Received: 26 January 2016 Accepted: 15 July 2016

Published online: 30 July 2016

\section{References}

1. Amato MB, Barbas CS, Medeiros DM, et al. Beneficial effects of the "open lung approach" with low distending pressures in acute respiratory distress syndrome. A prospective randomized study on mechanical ventilation. Am J Respir Crit Care Med. 1995:152:1835-46.

2. The Acute Respiratory Distress Syndrome Network. Ventilation with lower tidal volumes as compared with traditional tidal volumes for acute lung injury and the acute respiratory distress syndrome. N Engl J Med. 2000;342:1301-8.

3. Determann RM, Royakkers A, Wolthuis EK, et al. Ventilation with lower tidal volumes as compared with conventional tidal volumes for patients without acute lung injury: a preventive randomized controlled trial. Crit Care. 2010;14(1):R1

4. Pinheiro de Oliveira R, Hetzel MP, dos Anjos Silva M, et al. Mechanical ventilation with high tidal volume induces inflammation in patients without lung disease. Crit Care. 2010;14(2):R39.

5. Wilson MR, Patel BV, Takata M. Ventilation with "clinically relevant" high tidal volumes does not promote stretch-induced injury in the lungs of healthy mice. Crit Care Med. 2012;40:2850-7.

6. Serpa Neto A, Cardoso SO, Manetta JA, et al. Association between use of lung-protective ventilation with lower tidal volumes and clinical outcomes among patients without acute respiratory distress syndrome: a metaanalysis. JAMA. 2012;308:1651-9.

7. Kilpatrick B, Slinger P. Lung protective strategies in anaesthesia. Br J Anaesth. 2010;105 Suppl 1:1108-16.

8. Huntington JT, Royall NA, Schmidt CR. Minimizing blood loss during hepatectomy: a literature review. J Surg Oncol. 2014;109:81-8.

9. Nishimura T, Hasegawa N, Watanabe M, et al. Bronchoscopic microsampling to analyze the epithelial lining fluid of patients with pulmonary Mycobacterium avium complex disease. Respiration. 2008;76:338-43.

10. Takeuchi D, Yoshidome $H$, Kurosawa $H$, et al. Interleukin-18 exacerbates pulmonary injury after hepatic ischemia/reperfusion in mice. J Surg Res. 2010;158:87-93.

11. Ota S, Nakamura K, Yazawa T, et al. High tidal volume ventilation induces lung injury after hepatic ischemia-reperfusion. Am. J Physiol Lung Cell Mol Physiol. 2007;292:L625-31.

12. Michelet $P, D^{\prime} J$ ourno $X B$, Roch $A$, et al. Protective ventilation influences systemic inflammation after esophagectomy: a randomized controlled study. Anesthesiology. 2006;105:911-9.

13. Wolthuis EK, Choi G, Dessing MC, et al. Mechanical ventilation with lower tidal volumes and positive end-expiratory pressure prevents pulmonary inflammation in patients without preexisting lung injury. Anesthesiology. 2008; 108:46-54. 
14. Severgnini P, Selmo G, Lanza C, et al. Protective mechanical ventilation during general anesthesia for open abdominal surgery improves postoperative pulmonary function. Anesthesiology. 2013;118:1307-21.

15. Futier E, Constantin JM, Paugam-Burtz C, IMPROVE Study Group, et al. A trial of intraoperative low-tidal-volume ventilation in abdominal surgery. N Engl J Med. 2013;369:428-37.

16. Ladha K, Vidal Melo MF, McLean DJ, et al. Intraoperative protective mechanical ventilation and risk of postoperative respiratory complications: hospital based registry study. BMJ. 2015;351:h3646.

17. de Jong MA, Ladha KS, Melo MF, et al. Differential Effects of Intraoperative Positive End-expiratory Pressure (PEEP) on Respiratory Outcome in Major Abdominal Surgery Versus Craniotomy. Ann Surg. 2015;22 [Epub ahead of print].

18. Yang D, Grant MC, Stone A, et al. A Meta-analysis of Intraoperative Ventilation Strategies to Prevent Pulmonary Complications: Is Low Tidal Volume Alone Sufficient to Protect Healthy Lungs? Ann Surg. 2016;263(5):881-7.

19. Nakamura M, Fujishima S, Sawafuji M, et al. Importance of interleukin-8 in the development of reexpansion lung injury in rabbits. Am J Respir Crit Care Med. 2000;161:1030-6.

20. Komatsu Y, Yamamoto H, Tsushima $K$, et al. Increased interleukin-8 in epithelial lining fluid of collapsed lungs during one-lung ventilation for thoracotomy. Inflammation. 2012;35:1844-50.

21. Calfee CS, Eisner MD, Parsons PE, et al. Soluble intercellular adhesion molecule-1 and clinical outcomes in patients with acute lung injury. Intensive Care Med. 2009;35:248-57.

22. Bauer $\mathrm{T}$, Torres A, Ewig $\mathrm{S}$, et al. Effects of bronchoalveolar lavage volume on arterial oxygenation in mechanically ventilated patients with pneumonia. Intensive Care Med. 2001;27:384-93.

\section{Submit your next manuscript to BioMed Central and we will help you at every step:}

- We accept pre-submission inquiries

- Our selector tool helps you to find the most relevant journal

- We provide round the clock customer support

- Convenient online submission

- Thorough peer review

- Inclusion in PubMed and all major indexing services

- Maximum visibility for your research

Submit your manuscript at www.biomedcentral.com/submit

C Biomed Central 